Lata

Narayanaswamy

Dr Lata Narayanaswamy,

School of Politics and

International Studies

(POLIS), University of

Leeds, United Kingdom;

E-mail:

L.Narayanaswamy@

leeds.ac.uk

Julia Schöneberg

Dr Julia Schöneberg,

Department for

Development

and Postcolonial

Studies, University

of Kassel, Germany;

E-mail:

Julia.Schoeneberg@uni-

kassel.de

DOI: http://dx.doi. org/10.18820/24150479/ aa52i1/SP1

ISSN:0587-2405

e-ISSN: 2415-0479

Acta Academica $\cdot 2020$ 52(1): 1-9

(c) Creative Commons With Attribution (CC-BY)
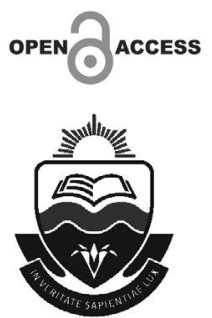

\section{Introduction to the Special Focus}

\section{Interrogating how we know the world - starting the conversation ...}

How do we 'know' the world? It is so vast a question that it feels, perhaps ironically, almost unknowable. Why does it matter? It is not a call to take an inventory of specific facts or perspectives, but is a question we ask in order to help frame a more critical and reflexive approach to the assumptions that underpin (academic) perceptions of WHAT counts as knowledge, HOW we capture and communicate that knowledge and WHO gets to both shape and present ideas as academic (read: expert) knowledge. Taken together, these reflections can, we believe, be very instructive and support more nuanced and critical approaches to social science scholarship.

This Special Focus is a continuation of encounters and conversations of a group of scholars and activists - in fact, most of us scholar-activists who came together in a workshop to discover that we, regardless of our geographical or institutional background, share similar frustrations regarding how we participate in (re)producing (post)colonial divides in the way we teach, research and collaborate. The red thread of our collective engagement continues to be our wrestling with questions of power in all its nuances and especially in relation to: doing research and being researchers; conceptualising teaching; and building collaboration and community among our own academic hierarchical (oftentimes neoliberal) settings and with those we claim to research. These areas are not distinct but rather overlap in important ways and affect how and with whom we engage. In bringing together this Special Focus, we have constituted ourselves as a Writing Collective, a 
processual challenge to the hierarchical tendencies of academic writing. It was important that we curated a process that embodied shared values of inclusivity, which was integral to our mission to challenge both what we know and how we know it.

First of all, who is 'we'? Who is included and who is not? Are we prepared to challenge our own expertise? 'We' are scholars from diverse fields in the social and natural sciences. Surprisingly, or perhaps not so, we quickly realised that struggles, discomforts and contestations were very similar among us regardless of whether our discipline was Peace Studies, Agro-Forestry, History, International Relations, Sociology, Development, Political Studies or Educational Sciences. Nevertheless, we need to ask: who is included and who is not?

Whereas many of us may face restrictions due to ethnic origin, gender or career status, generally, as academics, especially those of us based at institutions in the Global North, we are often in very privileged positions. We need to recognise positionality and privilege without resorting to a deterministic concept of identity and without letting this awareness lead us to paralysis. This paralysis very often emerges from the tendency for the answer to the question of 'power' being one of self-reflexivity - but how do we move beyond the tick-box of subjectivity to truly address the concerns around power imbalances in teaching, research and collaboration? How can reflexivity become a starting point to look outwards rather than as an exercise in introspection?

The question of how we tackle power imbalances in research processes emerges at the same time that we have witnessed a 'postcolonial turn' in relation to questions about the historical bases for how we approach issues of knowledge (co-)production, expertise and representation and which have gained significant momentum in academic discussions. It is a turn, as Dunford (2017: 382) reminds us, that starts with the recognition that: "different cosmovisions - ways of understanding the world - and different modes of living have been crushed, often violently, in the name of such particular perspectives masquerading as universal global designs."

While debates about 'whose knowledge counts' have and continue to rage in areas such as Development or Gender Studies (which in themselves are diverse academic fields rather than homogenous disciplines), questions about prevailing power and knowledge divides, represented by their respective 'canons', have only recently come to the fore in the wider social sciences. Disciplines such as International Relations, Cultural and Regional Studies and Politics are being challenged by movements such as 'Why is my curriculum white?' to confront rather than overlook colonial genealogies of contemporary politics, society and 
economy and thus acknowledge the way hegemonic discourses create and validate only particular types of knowledge.

Our starting point is the recognition that the question of whose knowledge, voice or idea counts emerges from our own collective academic subjectivity. So why does this matter? It may seem absurd to think that what, when and how academic 'knowledge' is constituted should be our central consideration, given that academia is often caricatured, unproblematically, as remote, the proverbial 'ivory tower' untroubled and far removed from the material realities of the 'real' world. Yet how we 'know' the world is underpinned by notions of 'expertise' that are meticulously framed as part of the perceived 'rigour' of Western academic engagement and developmentalist thinking (see Kothari, 2005; Narayanaswamy, 2017). The role played by Western higher education (HE) sits at the heart of that system: 'Far more so than Coca-Cola or Disney, it is the frameworks of knowledge, encapsulated in the academic disciplines, which have become universalized' (Lal, 2005: 124). As such, it matters a great deal to unsettling these 'frameworks' or imaginaries, what, when and how they are constituted in the first place and by whom. We require a more nuanced insight into the power relations underpinning how we KNOW the world and who has the power to shape and 'naturalise' this knowledge, both in terms of the ideas themselves and how these are codified.

What became clear throughout our workshop was the need to turn the lens on to the institutional structures and processes that shape the function and delivery of research and teaching in HE where many of us are located. As we shared stories, a picture slowly began to emerge, a shared picture of how HE challenges each one of us to pursue 'rigour' and 'originality', even as we are rarely if ever challenged ourselves to consider the wider ethics of our research in the first place. We learned that instead we struggled with these issues silently, worried that perhaps it is just us, that no one else will understand. As we ate and talked and laughed and got to know one another, some familiar and other surprising themes began to emerge.

One of the most pressing concerns to emerge from the workshop that has inspired this Special Focus is the question of how we communicate. The most blatant and persistent concern here is about the hegemony of English across the academy, an issue that surprised precisely no one and is reflected in a range of literature in this area (see Lins Ribeiro 1998; Mawdsley et al. 2002; Powell 2006; Nagar 2008). And not just any English, but a professionalised English, full of inaccessible jargon designed explicitly to underpin the expertise that Western academia is perceived as uniquely placed to nourish and cultivate (Narayanaswamy, 2017; 2019). But alongside this concern about language was revealed subtler or even invisible forms of control, both of what we know, and 
how this knowledge is both validated and communicated. Professionalisation policed not just our words but our bodies - what counts as appropriate clothing, hairstyles or make-up, which in itself had particular and predictable gendered dimensions (Lugones, 2008). We wondered about the idea of academic 'quality' and 'standards', dominated by exclusive, academic, peer-reviewed journals that are behind paywalls and near-impossible to access without institutional subscriptions. We gained these insights through sharing stories: of disquiet felt for indigenous voices anonymised, co-opted and then translated into 'data' in service of doctoral dissertations; pressure to only publish in high-impact journals; surprise when we learned that 'professionalisation' meant that Black African women are under pressure to straighten their hair because this looks 'smart'. We talked about the exploitation of our labour, of the precarity of postgraduate research, of the unrealistic expectations to string together multiple teaching contracts to make ends meet. The structural power of what and how we know in $\mathrm{HE}$ is incredibly lopsided in favour of mainly white men with little regard for the impact of the colonial past on our present and its intersectional effects.

One response to these concerns, increasingly shared by many working broadly in this intellectual space, has been to move beyond the notion of the 'postcolonial' - a terminology that 'emerged as an intellectual movement' rooted in cultural critiques and drawing principally from the South Asian colonial experience (Bhambra 2014). The language of 'decoloniality', drawing primarily from Latin American scholars, explicitly acknowledges that 'the inextricable combination of the rhetoric of modernity (progress, development, growth) and the logic of coloniality (poverty, misery, inequality), has to be central to any discussion of contemporary global inequalities' (Bhambra 2014: 119). As a collective, the language of 'decoloniality' is more attractive, centring our concerns about power. Our discussions revealed shared commitments to 'decolonise' curricula, research ideas, methodologies and approaches to partnership. What also became clear, however, was that our disciplinary and epistemological starting points were not always the same. For some of us, acknowledging our own (relative) power in relation to our research subjects and processes was the key, reflecting a belief that "You can never represent or act from an "outside", since you are always already situated inside discourse, culture, institutions, geopolitics' (Kapoor 2004: 640; drawing on Spivak 1990, 1993). For others, the starting point were questions around representation and appropriation, whereby we commiserated with concerns about 'how settler perspectives and worldviews get to count as knowledge and research and how these perspectives - repackaged as data and findings - are activated in order to rationalize and maintain unfair social structures' (Tuck and Yang 2012: 2). For all of us, there was a shared concern that our academic endeavours risked merely reproducing and entrenching the 
inequalities and hierarchies we sought to challenge and inadvertently reifying dominant, HE-bound knowledge frameworks (see Lal 2005). Our starting point in this Special Focus is that an absolute definition is not necessary, but rather, in keeping with our commitments to pluralism and inclusion, that we would instead strive to recognise and incorporate the different conceptualisations and practices that the term 'decolonising' signifies. We recognise that 'decolonising' HE is about challenging structures of thought and judgement, and that it is a difficult and ongoing process that we do not expect simply to 'complete', but rather a way of working and thinking and communicating that requires continuous engagement and reflection.

At the same time, we are aware that power is circular, there is a tension in us exercising power yet at the same time being rendered powerless in encounters with university administrations, publishing pressures and funder requirements - especially for those of us at a junior level of an academic career. We are all existing in a tense continuum of conflicting demands and tensions. We are part of the system that we are critiquing, and we recognise this. Yet, we are hopeful for pockets of rebellion that some of us have implemented, including our efforts as part of this Writing Collective.

Coming together as a collective we share solidarity but also discomforts. Our efforts together are designed to make these discomforts visible and productive, despite the very obvious limitations to turning our efforts into a transformative process. In confronting power and privilege as a collective, rather than lone strug'gle, we aim to use it more productively to pursue some of the goals that arose in our discussions, such as inclusion (of people, places and epistemologies), co-production and eventually social and epistemic justice (see Fricker 2007). In the contributions to follow we do not want to essentialise by trying to provide one-size-fits-all solutions; rather we aim to take the unfinished nature of what we can offer in the limited space of this Special Focus (both in terms of length, as well as in terms of format) as productive, yet subjective sharing to contribute to a larger tapestry of contestations that make up the process of 'decolonising.'

We understand this 'process' as a liberating approach to attend to the paralysis of self-reflexivity and discomforts of decolonisation, that remains committed to uprooting the deeply established injustices that continue to permeate academic (and other) knowledge production processes. Quite practically, in our way of working we have tried to uproot the individualistic and merit-based culture of academic writing and publication. Rather than sharing our views in single authored papers the writing teams have collaborated using online boards that were accessible to the whole collective at all times, thereby allowing us to cross-pollinate our thinking in a continuous evolutionary process of reviewing, 
commenting, writing and building on each other's contributions. We also made sure to come together as a group in frequent virtual meetings to discuss the direction of our writing and engage in convivial revision.

For us, these conversations are the start of a much larger and more important debate about not just how we 'know' the world, but why, both personally and professionally, reflecting on this question matters if we, as scholars, activists, teachers, parents, friends and, essentially, as human beings, are to confront the most urgent global development challenges, including climate change, prolonged conflict, prevailing white supremacist thinking, rising nationalism, racism and widening global inequality.

While the contributions of this Special Focus all take a different focus - the ethics of research, questions of critical reflexivity, politics of teaching, and epistemic (in-)justices in higher education - there are themes that run across all: (1) the politics of knowledge production and how problematic the term 'production' is in that context; (2) research/teaching (academia as such) as a very personal, relational endeavour that is a process rather than a one-off event; (3) the question of truths and their validity, linking to Western knowledge dominance, where these reflexive articulations not only clash with positivist assumptions around the nature of science, but also increasing neoliberal production/exploitation logics to which universities/institutions subscribe; and (4) the question of privileges, where hierarchical dynamics of North and South, professor and early-career researcher (ECR) shape actions towards unlearning privileges and subverting the dominant logics of knowledge production as we try to make space for knowledges and voices which have been silenced.

In the first article, Chris Millora, Siti Maimunah and Enid Still come together in their paper entitled 'Reflecting on the ethics of PhD research in the Global South: reciprocity, reflexivity and situatedness'. Their contribution explores ethical issues of positionality, reciprocity and reflexivity in conducting ethnographic fieldwork in the Global South as part of their PhD projects. The strength of their piece is not only the analysis of academic engagement against the backdrop of increasingly bureaucratised doctoral processes, but also the tensions they very personally encountered in conducting PhD fieldwork in Indonesia, India and the Philippines while enrolled in different Global North universities (in the UK and Germany).

In the second article, Grace Ese-osa Idahosa and Vanessa Bradbury commit to 'Challenging the way we know the world: overcoming paralysis and utilising discomfort through critical reflexive thought'. They outline attempts for overcoming paralysis and for utilising discomfort through critical reflexive thought and ask at what point can critical self-reflexivity become productive, rather than self-indulgent and paralysing? Reflecting on the assumptions that underpin our 
scholarship, they ask, how can we utilise emotions of paralysis, discomfort and contradiction towards positive social change?

Then, Su-ming Khoo, Witold Mucha, Christina Pesch and Cori Wielenga take on 'Epistemic (in)justice and decolonisation in higher education' and share experiences of a cross-site teaching project. Universities are places of research, teaching and debate, key actors in both the (re)production and the dissemination of (academic) knowledge(s). These dynamics demand further reflection and problematisation. The authors draw on experiences from South Africa and Germany.

Finally, Zeynep Gulsah Capan, Sebastian Garbe and Michaela Zöhrer come together in a trialogue on 'How do we teach the world?'. Their interaction, like almost every good and inspiring conversation, has developed its own dynamics. It was for this very reason that they decided to start with a recorded discussion: in conversations or joint exchanges, even where these may not seem very controversial, questions emerge that otherwise may not be addressed, perhaps revealing new ideas or old silences. In that sense, they actively practice the idea of (un-)learning from each other and of (un-)learning together in their deliberations on teaching at the university and challenging teaching practices entrenched within frames of colonialism, racism and Eurocentrism.

This Special Focus is not about trying to find answers. Rather, we embarked on this project to find out where and how these dilemmas might lead to exploring tensions and complexities that in turn shape a response that challenges the visible and invisible structural constraints in HE. We decided that we need to ask critical questions about the voices, views and ideas we seek out, as well as how we gather and then choose to codify and represent them and the claims to 'expertise' these ultimately represent. We agreed on the need to reflect on the mechanisms or codes through which we 'know' the world, and how these are shaped by interconnected life worlds, outwardly interacting, creating continuities and discontinuities and new forms of knowledge. We need to ask whose ideas are being validated and whose ideas hidden as a result of the structural power of $\mathrm{HE}$ knowledge systems. And we all agreed that we should start by asking whether we are even the right people to be asking the question in the first place.

That's what we tried to do. For this reason, the invitation to publish with Acta Academica was key to supporting some of our key objectives, notably open access that allows these ideas to percolate outside of paywalls to become part of 'decolonising' efforts. Based in South Africa, working with this journal also supported our shared commitment to challenging the dominance of Northernbased publishers. 
We need to acknowledge some limitations too. Despite being a multilingual group, and despite our conscious attempts to engage in polylogue this Special Focus is presented exclusively in a dominant and, at times, professionalised academic English language. It is presented in an exclusively written format, and although the trialogues included in the contributions are far from a mainstream academic norm, our collaborative work is featuring no alternative forms of expression other than written text. In acknowledging these limitations, we invite comment and engagement on how the ensuing discussions might inform future directions, but also how we might learn from the 'decolonising' efforts of others.

So here is our Special Focus setting out the beginning of a response to these myriad challenges, how we might start to 'know' the world differently. It is not a finished product but hopes to be part of a wider process, through which many of us will seek to continue these conversations and collaborations.

\section{Acknowledgement}

We gratefully acknowledge financial support provided by the European Association of Development Research and Training Institutes (EADI) that enabled the organisation of the initial workshop and subsequently facilitated the participation of members of the collective in the Annual Conference of the Millennium Journal (London, 19-20 October 2019), where first insights on content and process were presented. We also thank the participants at the conference interactive session for their comments and sharing personal reflections on the topic.

\section{Bibliography}

Bhambra GK. 2014. Postcolonial and decolonial dialogues. Postcolonial Studies. 17(2): 115-121. https://doi.org/10.1080/13688790.2014.966414

DUNFORD R. 2017. Toward a decolonial global ethics. Journal of Global Ethics 13(3): 380-397. https://doi.org/10.1080/17449626.2017.1373140

FRICKERM. 2007. Epistemicinjustice: powerand theethics of knowing. Oxford:Oxford University Press. https://doi.org/10.1093/acprof:oso/9780198237907.001.0001

KAPOOR I. 2004. Hyper-self-reflexive development? Spivak on representing the Third World 'Other'. Third World Quarterly 25(4): 627-647. https://doi.org/10.1 080/01436590410001678898

KOTHARI U. 2005. Authority and expertise: The professionalisation of international development and the ordering of dissent. Antipode 37(3): 425-446. https:// doi.org/10.1111/j.0066-4812.2005.00505.x

LAL V. 2005. Empire of knowledge: culture and plurality in the globaleconomy. New Delhi: Vistaar Publications. 
LINS RIBEIRO G. 1998. Latin American feminisms "go global": trends of the 1990s and challenges for the new millennium. In: Alvarez SE, Dagnino E and Escobar A (eds). Cultures of politics politics of culture: re-visioning Latin American social movements. Colorado: Westview Press.

LUGONES M. 2008. The coloniality of gender. Worlds \& Knowledges Otherwise 2 (Spring): 1-17.

NAGAR R. 2008. Languages of collaboration. In: Moss P and Falconer Al-Hindi K (eds). Feminisms in geography: rethinking space, place, and knowledges. Lanham: Rowman and Littlefield Publishers.

NARAYANASWAMY L. 2019. Deeds not words: the marginalizing effects of global gender equality norms. In: Engberg-Pedersen L, Fejerskov AM and ColdRavnkilde SM (eds). Rethinking gender equality in global governance: the delusion of norm diffusion. London: Palgrave Macmillan. https://doi. org/10.1007/978-3-030-15512-4_10

NARAYANASWAMY L. 2017. Gender, power and knowledge for development. London: Routledge. https://doi.org/10.4324/9781315816975

POWELL M. 2006. Which knowledge? Whose reality? An overview of knowledge used in the development sector. Development in Practice 16(6): 518-532. https://doi.org/10.1080/09614520600957951

Mawdsley E, Townsend J, Porter G, and Oakley P. 2002. Knowledge, power and development agendas: NGOs North and South. Oxford: INTRAC.

SPIVAK GC. 1993. Outside in the teaching machine. New York and London: Routledge.

SPIVAK GC. 1990. The post-colonial critic. In: Harasym S (ed). The post-colonial critic: interviews, strategies, dialogues. London: Routledge.

TUCK E, AND YANG KW. 2012. Decolonization is not a metaphor. Decolonization: Indigeneity, education \& society, 1(1): 1-40. 